\title{
Overcoming Physical, Financial, Mental and Sexual Harassment in Postgraduate Medical Residency in India
}

\author{
Sarabjeet CHHABRA ${ }^{a}$
}

With a great sense of accomplishment, content, and happiness, having passed one of the most competitive medical entrance examinations in India, a resident joins a residency program after a tedious and exhausting year, or sometimes more, of rigorous studying, endless preparatory tests, and socially isolating from the rest of the world. Admission in a reputed postgraduate government medical college becomes his only objective which he somehow anticipates would expand his reputation in the real medical world after another three years of his postgraduate degree. Entry into the postgraduate program instils confidence, self-respect, passion, and enthusiasm to learn and master the respective field.

Little does he know that this hint of success and joy is rather short-lived, and the newly acquired confidence and self-respect is about to be trampled upon by the egoistic and irrational organizational hierarchy, and widespread bullying by senior medical residents, consultants, and professors (1-3). Contrary to the consultants and professors in medical colleges who are permanent government employees and have their working hours specified by government orders, postgraduate residents, on the other hand, are temporary contractual employees hired to satisfy the personal and financial desires of seniors, with no fixed duty hours, and meagre pay, who in no circumstance can voice an opinion or express resentment to the stressful working conditions as he may be terminated from the residency program without assigning any reasons (4). Should there be a resident holding ground against this mistreatment, he is pressurized from his department and the administration, asked to clock in even longer working hours especially night duties without any weekly offs, and threatened against approving his thesis work; and even if somehow, under this immense victimization, he manages to not succumb physically and mentally, his guaranteed failure in final examinations is a surety. Given the shortage of postgraduate medical seats when compared to undergraduate seats in India, it is almost impossible for a resident to surrender his hard earned and rightful seat when legally bound contracts and high valued monetary bonds have paved a way in as a prerequisite while securing a medical postgraduate program $(5,6)$.

As a human being, our body can only take a limited amount of toll when working relentlessly and tirelessly, often 12 hours at a stretch or in some institutes even more than 24 hours, 7 days a week, even when Honourable Supreme Court in its judgment dated, 25.9.87, in writ petition No. 348-352 of 1985 directed all the State Governments, Medical Institutions and Universities to amend their rules and regulations to introduce a uniform residency scheme by 1993. Following these orders, Ministry of Health \& Family Welfare, Government of India had sent directive to all states \& Union territory administrations vide letter No. S-11014/3/91/ME (P) dated 05 June, 1992 where in the instruction no.13 of this letter 'Hours of Work', it is mentioned that "Continuous active duty for resident doctors will not normally exceed 12 hours per day. Subject to exigencies of work the resident doctors will be allowed one weekly holiday by rotation. The resident doctors will also require to be on call duty not exceeding 12 hours at a time. The junior Residents should ordinarily work for 48 hours per week and not more than 12 hours at a stretch subject to the condition that the working hours will be flexible as may be decided by the Medical Superintendents concerned keeping in view the workload and availability of doctors for clinical work." $(7,8)$. However, to our dismay, no State government or medical colleges follow the directed orders making a mockery of the highest legal establishment of India. Even the

${ }^{2}$ Uzm. Dr., Department of Anaesthesia and Intensive Care, Government Medical College and Hospital, Chandigarh, India $\square$ drsarabjeetchhabra@hotmail.com Gönderim Tarihi: 10.01.2021 • Kabul Tarihi: 19.03.2021 
International Labor Organization in 1962 recommended prohibition of more than 48 hours of work per week, and the Factories Act of India also recommends payment of overtime and holidays for work more than 48 hours a week $(9,10)$. Unfortunately, no heed is payed to the resident workforce responsible for entertaining the major burden of the hospitals raising a huge moral and ethical question to the administration and the government. In addition to discharging the hospital duties involving patient care and academic obligations, many residents are forced to carry out personal work for senior consultants, denying of which often leads to humiliation, discrimination and sometimes assault (11). Shadow of slavery? The anxiety, chronic sleep deprivation, and the constant physical harassment due to the above factors lead to excessive burden, poor performance and altered thought process of the medical resident which ultimately leads to mistakes and hampers patient care; resident again on the receiving side facing the brunt of the blame.

On the financial front, apart from paying excessive fees in the name of tuition fees, caution fees, academic fees, security deposits, amalgamated fund etc for postgraduate seat, it so happens very often that medical residents are forced by senior faculty to register for paid organizations, journal subscriptions and/or conferences against the residents' will, which also aids to the financial burden of the resident already living on an irregular and miniscule stipend (12). Not to forget the illegality and unethicality of it. In addition to the above, pleasing the senior consultants and professors has almost become a necessity for residents in India, in an attempt to avoid the irrational mood displacements, discrimination, and being the 'punching bags', by offering them gifts, conducting social gatherings, or in some instances buying their household groceries (13). This story takes a turn for even worse in a resident's life should he be married or supporting his parents which creates friction between his own family members at the expense of safeguarding his degree that ultimately causes suffering to the whole family. Divorces and separations are commonly reported in substantial numbers during first year of postgraduate life (14).

Multiple instances of sexual and mental harassment from India and all over the world have come to light in recent times questioning the postgraduate residency system (15-20). Be it in the form of gender discrimination, disrespectful jokes about sex, commenting on someone's physical appearance or unwelcoming physical contact, singling someone out for grilling or interrogation, ridicule, verbal abuse, threats with failure or giving poor evaluations, intimidatory use of disciplinary procedures, and reprisal or threat of reprisal for negative feedback like lodging of a false and fabricated complaint or grievance dangles a sharp sword on the career prospects of the resident along with a grave impact on the psychological and emotional wellbeing. The repeated mental assaults have a profound negative and detrimental impact on the academic and social performance of the residents which in turn leads to increased incidence of anxiety disorders, sleep disorders, eating disorders, posttraumatic stress disorder, substance abuse, depression, and suicide attempts among residents (21-25). India has the one of the highest rates of depression and suicides among resident doctors where $90 \%$ of the residents reported burnout, 30\% reported major depression and $16.7 \%$ had suicidal ideations which has become a public health issue $(26,27)$. The plights of resident doctors are either subverted or ignored by their own department or the hospital administration in order to avoid unnecessary attention and defamation from rest of the medical fraternity or the general population. This further demoralizes residents when they try to voice their reservations resulting in an endless loop of intimidation, harassment and humiliation finally concluding in either leaving the postgraduate program or, the socially unacceptable, 'suicide', again for which the ultimate blame lies on the resident himself of not being of a sound mind and character.

There is no scarcity of advices, suggestions and recommendations on the coping mechanisms for residents facing harassment at multiple levels. As suggested by Dr. Gude, and I quote "Embracing inspiration regardless of the source, caution in clinical procedures, developing endurance, inculcating magnanimity, and putting patients' care first while perpetually updating themselves with advances in medicine, help residents gain focus and stick to ideals in an unencumbered manner. Exercising religiously, austere discipline in time and 
finance management, displaying adequate gratitude, and acknowledgment for spousal / partner support, spreading cheer, unwinding in a responsible manner, proper sleep hygiene, and staying away from any kind of substance abuse are some of the ways residents can fight the formidable strain of residency." (14). All the measures mentioned here sound appropriate, and should appeal to all the residents. However, 'in an ideal world', equal academic contribution and mutual respect between the residents and senior consultants and professors would benefit a great deal in improving the learning, confidence, passion and loyalty of a medical resident towards his field, and thus raising the standards of medical education system in India. How near or far are we from the 'ideal world'?

Shouldn't be now the need of the hour to call for a stop on the constant badgering and belittlement of the major backbone of the medical system. To say a big 'NO' to the unreasonable and impudent demands and harassment faced by the postgraduate residents. Or should we wait until a few more, a hundred more, or probably a thousand more, residents surrender their lives to the seniority based egoistic Indian legacy. May be the question is too harsh and unintentionally disrespectful to ask, but the time is for YOU to ANSWER.

\section{REFERENCES}

1. Lempp H, Seale C. The hidden curriculum in undergraduate medical education: Qualitative study of medical students' perceptions of teaching. BMJ 2004;329:770-3.

2. Ahmer S, Yousafzai AW, Siddiqi M, Faruqui R, Khan R, Zuberi S. Bullying of trainee psychiatrists in Pakistan: A cross-sectional questionnaire survey. Acad Psychiatry 2009;33:335-9.

3. Bairy KL, Thirumalaikolundusubramanian P, Sivagnanam G, Saraswathi S, Sachidananda A, Shalini A. Bullying among trainee doctors in Southern India: A questionnaire study. J Postgrad Med 2007;53:87-90.

4. Agreement for PG course students. Url:http://gmch.gov.in/sites/default/files/2019-08/46.pdf

5. Manipal University. Prospectus 2020. Available at: https:/manipal.edu/content/dam/manipal/mu/documents/ Admissions/adm2020/MAHE\%20Prospectus\%202020.pdf

6. Government Medical College \& Hospital, Chandigarh. Prospectus for admission to MD/MS courses (session 2019). Available at: http://www.gmch.gov.in/sites/default/files/documents/mdms_prospectus2019.pdf

7. Honorable Supreme Court in its judgment dated, 25.9.87, in writ petition No. 348-352 of 1985.

8. Letter No. S-11014/3/91/ME (P) dated 05 June, 1992.

9. International Labour Organisation, R116 Reduction of Hours of Work Recommendation 1962.

10. Ministry of Labour and Employment, The Factories Act, Directorate General Factory Advice Service and Labour Institutes (DGFASLI), 1948. Available at: http://business.gov in/legal_aspects/factories_act.php.

11. Meghna A Singhania. Medical council of India to look into Harassment of Junior Residents at Medical Colleges. 15 August 2018. Available at: https://medicaldialogues.in/medical-council-of-india-to-look-into-harassment-ofjunior-residents-at-medical-colleges

12. Shah B, Shah V, Shah C. Residency training programme in a Tertiary Care Hospital of Gujarat. J Health Manag 2010;12:65.

13. Suyash Karangutkar. JJ Hospital junior resident doctor accuses professor of harassment. February 19, 2019. Available at: https://www.thehindu.com/news/cities/mumbai/jj-hospital-junior-resident-doctor-accuses-professorof-harassment/article26306796.ece

14. Gude D. A Slice of a Postgraduate Medical Resident's Life. Mens Sana Monogr 2012;10:189-93.

15. Rupsa Chakraborty. 'Resident doctors being mentally harassed. Apr 2, 2016. Available at: https://www.asianage. com/mumbai/resident-doctors-being-mentally-harassed-194

16. 'MARD' fights for women doctors facing harassment. Aug 19, 2018. Available at: https://timesofindia.indiatimes. $\mathrm{com} / \mathrm{city} / \mathrm{mumbai} / \mathrm{mard}$-fights-for-women-doctors-facing-harassment/articleshow/65456975.cms

17. Accused of sexual harassment, GMCH doctor resigns. January 15, 2020. Available at: https://www.tribuneindia. $\mathrm{com} /$ news/chandigarh/accused-of-sexual-harassment-gmch-doctor-resigns-26681 
18. Binder R, Garcia P, Johnson B, Fuentes-Afflick E. Sexual harassment in medical schools: the challenge of covert retaliation as a barrier to reporting. Acad Med 2018;93(12):1770-73.

19. Phillips SP, Webber J, Imbeau S, Quaife T, Hagan D, Maar M, et al. Sexual harassment of canadian medical students: a national survey. EClinicalMedicine 2019;7:15-20.

20. Launer J. Sexual harassment of women in medicine: a problem for men to address. Postgrad Med J 2018;94(1108):129-30.

21. Resident doctors of AIIMS write to Union minister over harassment of colleague who attempted suicide. 19 April 2020. Available at: https://www.outlookindia.com/newsscroll/resident-doctors-of-aiims-write-to-union-ministerover-harassment-of-colleague-who-attempted-suicide/1807916

22. Shinsako SA, Richman JA, Rospenda KM. Training-related harassment and drinking outcomes in medical residents versus graduate students. Subst Use Misuse 2001;36(14):2043-63.

23. Al-Shafaee M, Al-Kaabi Y, Al-Farsi Y, White G, Al-Maniri A, Al-Sinawi H, et al. Pilot study on the prevalence of abuse and mistreatment during clinical internship: a cross-sectional study among first year residents in Oman. BMJ Open 2013;3(2):1-7.

24. Nagata-Kobayashi S, Maeno T, Yoshizu M, Shimbo T. Universal problems during residency: abuse and harassment. Med Educ 2009;43(7):628-36.

25. Loerbroks A, Weigl M, Li J, Glaser J, Degen C, Angerer P. Workplace bullying and depressive symptoms: a prospective study among junior physicians in Germany. J Psychosom Res 2015;78(2):168-72.

26. Grover S, Sahoo S, Bhalla A, Avasthi A. Psychological problems and burnout among medical professionals of a tertiary care hospital of North India: A cross-sectional study. Indian J Psychiatry 2018;60:175-88.

27. Bindu Shajan Perappadan. Suicide among doctors a public health crisis, says IMA. March 31, 2018. Available at: https://www.thehindu.com/news/cities/Delhi/suicide-among-doctors-a-public-health-crisis-says-ima/ article23396037.ece 